DOI: $10.1515 /$ sgem-2017-0021

\title{
MODELLING SPILLWAY FLOW CONDITIONS AT ZŁOTNIKI STORAGE RESERVOIR ON THE KWISA RIVER
}

\author{
JERZY MACHAJSKI \\ Department of Geotechnics and Hydrotechnics, Wrocław University of Technology, \\ Wybrzeże Wyspiańskiego 27, 50-370 Wrocław, e-mail: Jerzy.Machajski@pwr.wroc.pl
}

\section{DOROTA OLEARCZYK}

Department of Environmental Engineering, Wrocław University of Environmental and Life Sciences, Plac Grunwaldzki 24, 50-364 Wrocław, e-mail: Dorota.Olearczyk@up.wroc.pl

\begin{abstract}
An important part of the work connected with planning modernization of outlet devices of Złotniki storage reservoir on the Kwisa river was numerical modelling of flow conditions in the flume of the side-channel spillway. The modelling was preceded by the analysis of operating principles of such a device and performing analytical calculations that defined the spillway capacity ability as a function of the required water levels in the reservoir and the conditions of water flow through the flume that are significant to spillway operation. The results of the numerical modelling performed pointed to the evident need to reconstruct this device, guaranteeing exploitation safety of the reservoir, mainly in view of the computational discharges, exceeding considerably the nominal capacity ability of the reservoir's outlet installation in the existing constructional state.
\end{abstract}

\section{INTRODUCTION}

According to the Building Regulations, every structure should meet definite technological requirements, e.g., in terms of its location. For hydrotechnical structures, first requirements were defined by the so-called Technical Regulations, published in 1967 and changed to Technical Conditions in 1973. These regulations included requirements set out for structures of a given class of importance. The next Technical Conditions were issued in 1996 and they were in force until 2007, when current requirements were published [9]. The 1996 Technical Conditions contained major changes concerning the requirements for hydrotechnical structures of a given class of importance. As a result, a number of structures of this type in Poland had their class of importance changed, together with the appropriate requirements including those concerning computational discharges.

For the Złotniki storage reservoir discussed, the change in technical conditions introduced by the Regulations from 1996 resulted in changing its class of importance from II to I, which involved a change in design and control of computational discharges. Then the question arose whether the new operating conditions would allow 
passing increased discharges safely through the existing outlet devices. The authors of this publication have attempted to solve the resultant problem.

\section{STRUCTURE CHARACTERISTICS}

The principal function of the multi-task Złotniki reservoir, whose dam was built at the $95+540$ kilometre of the Kwisa river, is storing water for energy production purposes, and to a limited extent - flood protection of the downstream river valley $[4,5]$. The $36 \mathrm{~m}$ high dam creates a reservoir with the maximum storage capacity of 12.10 million $\mathrm{m}^{3}$. The structure was built in 1924-1927, and the arch-shaped body of the dam was built of crushed stone in concrete. In the period of the most frequent occurrence of floods (June-October), the reservoir has a constant storage capacity, equal to 1.60 million $\mathrm{m}^{3}$. A plan of the dam and the accompanying structures of Złotniki reservoir is shown in Fig. 1.

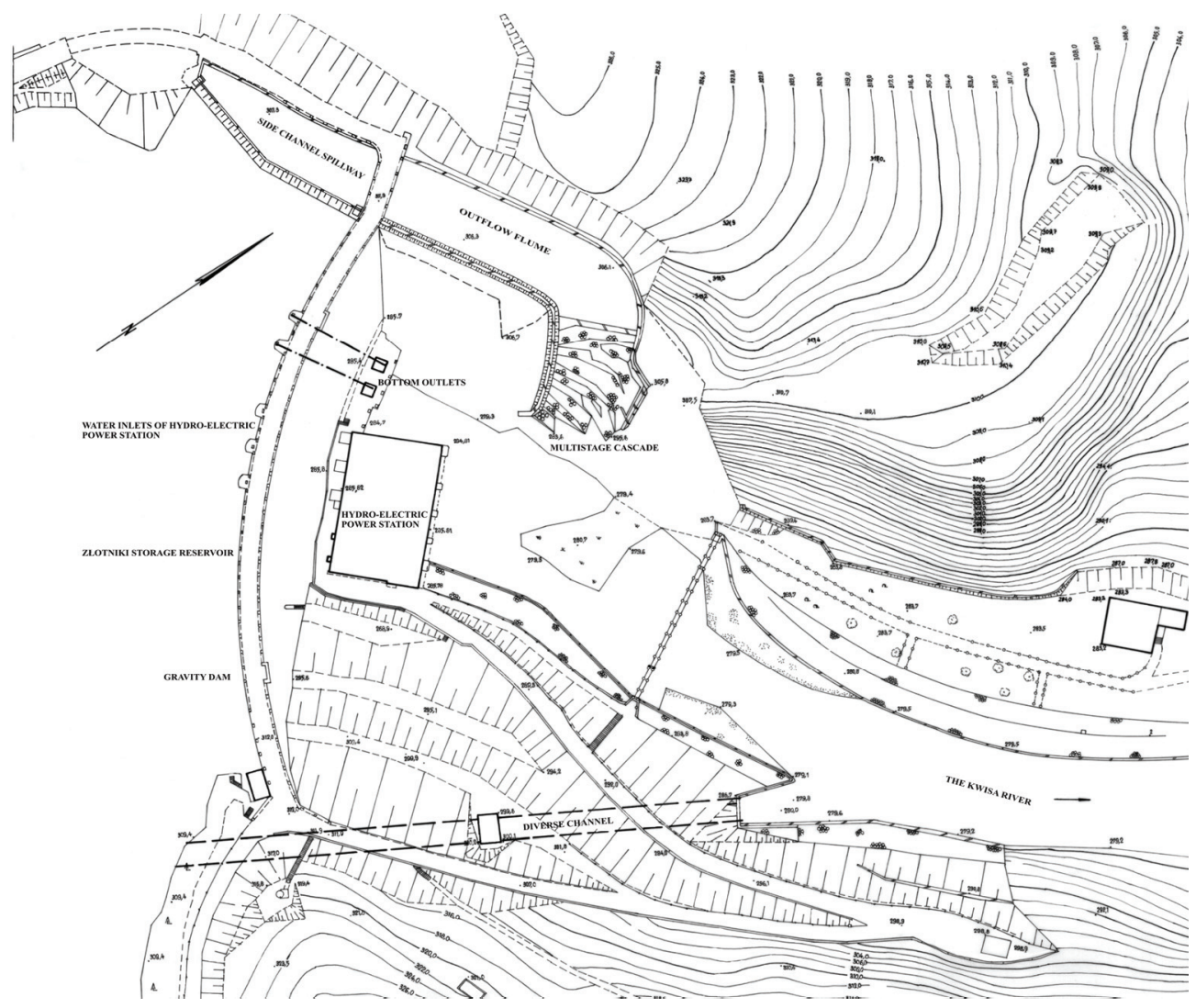

Fig. 1. Functional plan of the Złotniki dam 


\section{OUTLET DEVICES}

Surplus water is released through outlet devices, which comprise: a diverse channel, two bottom outlets with diameters of $1400 \mathrm{~mm}$ and $1000 \mathrm{~mm}$, and a sidechannel spillway. The main outlet device of the reservoir is a two-span spillway with the length of $22.50 \mathrm{~m}$ each, with $0.70 \mathrm{~m}$ high flap gates, separated by a $2.0 \mathrm{~m}$ wide concrete pillar. The spillway starts working at the moment when the water level elevation in the reservoir reaches the datum of its crest, equal to $309.30 \mathrm{~m}$ a.s.1., which corresponds to the reservoir storage capacity of 9.70 million $\mathrm{m}^{3}$. The water released from the spillway, flowing along the c. $50 \mathrm{~m}$ long flume and through an outflow channel with a similar length, enters the cross-section of a multistage cascade formed in a rock massif closing the Kwisa river valley from its left bank. The diverse channel was cut out in the rock mass in the form of a $4.40 \mathrm{~m}$ high and $5.60 \mathrm{~m}$ wide tunnel with the total length of $150 \mathrm{~m}$. Halfway down, the tunnel is divided by a vertical shaft with elliptical cross-section of $2.95 \mathrm{~m} \times 5.30 \mathrm{~m}$, with two conduits DN 1400, equipped with valve gates, built in the bottom part of its section. Bottom outlets consist of two conduits of DN 1400 and DN 1000 in diameter, equipped with valve gates on the upstream and downstream sides. Water is supplied to the turbine through three independent pipelines with diameters of DN 1800 , DN 1700 and DN 1600, with inlets placed on the downstream face of the dam. The power plant is equipped with three turbogenerators of total power of $4.42 \mathrm{MW}$, with installed capacity of $20.29 \mathrm{~m}^{3} \mathrm{~s}^{-1}$ and mean water head of $28 \mathrm{~m}$ in the water level elevation of $312.0 \mathrm{~m}$ a.s.l. (dam crest datum) [4, 5].

\section{CAPACITY ABILITY OF OUTLET DEVICES}

The capacity ability of outlet devices of Złotniki reservoir is specified for water levels reaching the dam crest $[4,5]$. The total capacity of the side channel spillway, for two spans with opened flap gates, was estimated by the German designers of the structure to be about $380.80 \mathrm{~m}^{3} \mathrm{~s}^{-1}$. The capacity ability of bottom outlets was verified by field measurements: for the conduit of diameter DN $1400-31.20 \mathrm{~m}^{3} \mathrm{~s}^{-1}$, and for the one with diameter DN $1000-15.40 \mathrm{~m}^{3} \mathrm{~s}^{-1}$. The capacity of diverse channel for two installed conduits of diameter $1400 \mathrm{~mm}$ each was determined in a similar way, based on field measurements equal to $56.80 \mathrm{~m}^{3} \mathrm{~s}^{-1}$.

According to the actual water law permission, the maximum valid capacity ability of outlet devices is $484 \mathrm{~m}^{3} \mathrm{~s}^{-1}$, of which $380 \mathrm{~m}^{3} \mathrm{~s}^{-1}$ flow over the side spillway and the cascade. The capacity of the outlet devices of Złotniki reservoir is shown in Table 1, and is overestimated by ca. $130 \mathrm{~m}^{3} \mathrm{~s}^{-1}$, which results from the wrong assumption made by the German designers, who described the hydraulic operating conditions of the side channel spillway as not submerged, while in fact it works as a submerged one (Fig. 3). 
Total capacity ability of outlet devices of Złotniki reservoir (according to German calculations)

\begin{tabular}{|c|c|c|c|c|c|c|}
\hline Water level & Elevation & $\begin{array}{l}\text { Diverse } \\
\text { channel }\end{array}$ & $\begin{array}{c}\text { Bottom outlet } \\
\text { DN } 1400\end{array}$ & $\begin{array}{l}\text { Bottom outlet } \\
\text { DN } 1000\end{array}$ & Spillway & Total \\
\hline & [m a.s.l.] & {$\left[\mathrm{m}^{3} \mathrm{~s}^{-1}\right]$} & {$\left[\mathrm{m}^{3} \mathrm{~s}^{-1}\right]$} & {$\left[\mathrm{m}^{3} \mathrm{~s}^{-1}\right]$} & {$\left[\mathrm{m}^{3} \mathrm{~s}^{-1}\right]$} & {$\left[\mathrm{m}^{3} \mathrm{~s}^{-1}\right]$} \\
\hline Min. PP & 303.03 & 47.40 & 26.30 & 12.80 & - & 86.50 \\
\hline NPP (summer) & 309.30 & 54.20 & 29.80 & 14.60 & - & 98.60 \\
\hline NPP (winter) & 310.04 & 55.00 & 30.20 & 14.70 & 49.88 & 149.78 \\
\hline Max. PP & 311.30 & 56.10 & 30.70 & 15.20 & 235.0 & 337.10 \\
\hline \multirow{2}{*}{ Dam crest } & \multirow{2}{*}{312.0} & 56.80 & 31.20 & 15.40 & \multirow{2}{*}{380.80} & \multirow{2}{*}{484.20} \\
\hline & & \multicolumn{3}{|c|}{$\Sigma 103.40$} & & \\
\hline
\end{tabular}

\section{ANALYTICAL CALCULATIONS}

A side channel spillway combines the simultaneous operation of the weir part and the flume conveying water, usually running parallel to the spillway edge. The function of this channel is to take over all the water flowing over the spillway and conveys it to devices connecting the side channel spillway with the downstream river section. Analyses of water movement conditions within side channel spillways have been changing gradually. Currently $[1,3,6,10,11,12]$, an analysis based on the law of conservation of linear momentum (the amount of motion) is available. It assumes that the only force ensuring water flow in the flume results from the slope of water level in the direction of its movement. Moreover, the energy of water flowing over the spillway crest is usually dissipated as a result of its mixing with water flowing through the flume and it does not influence flow conditions in the flume. Therefore, the objective of hydraulic calculations of side channel spillways is to define the required length of the spillway crest, with the assumed reservoir exploitation conditions, and to define the pattern of water table lines in the spillway flume, with adopted parameters of flume cross-section, constant slope of its bottom lines and constant increase of discharge rate over the flume length $[1,3,6,10$, $11,12]$.

Spillway discharge was determined on the assumption that the device will operate as not submerged in the whole range of expected discharges. The calculations employed a formula describing the work of free spillway with a straight insert on its crest, in the form $[3,6,8,10,12]$

$$
Q=\varepsilon 2 / 3 \mu B \sqrt{2 g} H_{0}^{3 / 2}
$$


where:

$\varepsilon$-weir side contraction coefficient, for the discussed case $\varepsilon=1.0$,

$\mu$-discharge coefficient, for the discussed case $\mu=0.654$,

$B$ - length of spillway crest, for the analysed case $B=45.0 \mathrm{~m}$,

$H_{0}$ - energy height calculated in relation to spillway crest.

For calculation purposes, the authors adopted the water elevation in reservoir resulting from water level in relation to the spillway crest $(309.30 \mathrm{~m})$ and the dam crest, determining the thickness of water layer and the resultant stream energy. The following results were obtained: 312.00 (dam crest) $-309.30=2.70 \mathrm{~m} \rightarrow Q=$ $385.58 \mathrm{~m}^{3} \mathrm{~s}^{-1}$.

For further analyses concerning the parameters of the side channel spillway flume, the above value of computational discharge was assumed.

According to the currently available classification of water flow in open channels $[2,8]$, water movement in flume of side channel spillways is categorized as a spatially varied steady flow. Therefore, when determining the parameters of the flume, one should consider, in compliance with Newton's second principle of motion, the influence of external forces analysed in two adjacent cross-sections 1-1 and 2-2, spaced at $d x$, including gravity force enabling water motion, the impact of roughness of channel cross-section material and the force resulting from the difference in hydrostatic pressures acting in the two chosen cross-sections (Fig. 2).

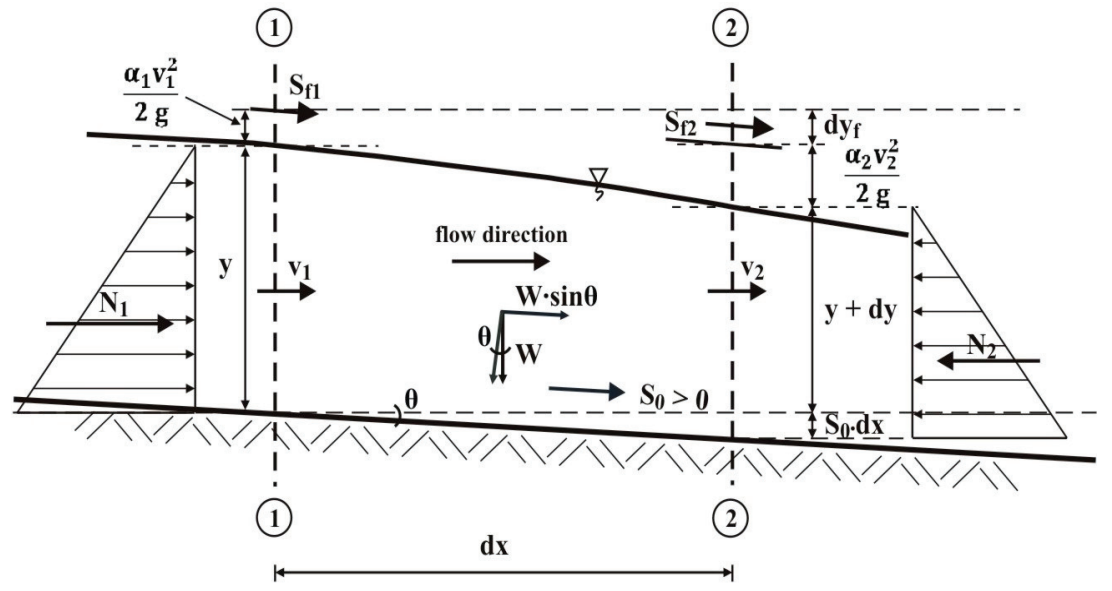

Fig. 2. Computational dimensioning scheme of a spillway flume

Gravity is represented by the horizontal component of water weight $W$, between two cross-sections $1-1$ and 2-2, usually expressed as the relation $[1,3,6,10]$

$$
W \sin \theta=\gamma S_{0} A d x
$$


where:

$S_{0}$ - longitudinal slope of flume bottom line,

$A$ - wetted area between cross-sections 1-1 and 2-2,

$\gamma$ - specific weight of water,

$\theta$-inclination angle of the flume bed.

The force resulting from the impact of roughness of the flume material can be expressed in the form $[1,3,6,10]$

$$
F_{s}=\gamma A S_{f} d x
$$

where $S_{f}$ - energy line slope.

The force resulting from the difference in hydrostatic pressures acting on cross sections 1-1 and 2-2 respectively, could be expressed as $[1,3,6,10]$

$$
N_{1}-N_{2}=-\gamma A d y
$$

where:

$N_{1}$ - hydrostatic pressure force acting in cross-section 1-1,

$\mathrm{N}_{2}$ - hydrostatic pressure force acting in cross-section 2-2,

$d y$ - depth difference between cross-sections 1-1 and 2-2,

The resultant change in the amount of momentum in time unit between crosssections $1-1$ and $2-2$ is then equal to the sum of external forces and it is described by the equation $[1,3,6,10]$

$$
\frac{d M}{d t}=N_{1}-N_{2}+W \sin \theta-F_{s} .
$$

Once we substitute $A=Q / v, q=d Q / d x$ and perform appropriate transformations, the following relation will be obtained $[1,3,6,10]$ :

$$
\frac{d y}{d x}=\frac{S_{0}-S_{f}-2 \alpha Q q / g A^{2}}{1-\alpha Q^{2} / g A^{2} D}
$$

where:

$\alpha$ - kinetic energy correction factor (Saint Venant's), $\alpha=1.10$,

$q$ - flow growth per unit of flume length, $d Q / d x$,

$D$ - hydraulic depth, $D=A / B$,

$B$ - width of the flume $B=15 \mathrm{~m}$.

The solution of the above differential equation can be two-fold: either applying available numerical methods or simplified methods, consisting of replacing differentials with finite differences.

For instance, the difference equation defining the change of water level $\Delta y$ over the length $\Delta x$ assumes the following form $[1,3,6,10]$ 


$$
\Delta y=-\frac{\alpha Q_{1}\left(v_{1}+v_{2}\right)}{g\left(Q_{1}+Q_{2}\right)}\left[\left(v_{2}-v_{1}\right)+\frac{v_{2}\left(Q_{2}-Q_{1}\right)}{Q_{1}}\right]+S_{0} \Delta x-S_{f} \Delta x .
$$

Analytical calculations performed according to this relation confirmed a possibility of obtaining the spillway capacity ability of $400 \mathrm{~m}^{3} \mathrm{~s}^{-1}$, but only when it operates as a not submerged spillway. Once water enters the cross-section of the flume, in its existing solutions it is promptly overfilled and starts working as a submerged one. Therefore the results of spillway capacity ability calculations, transferred onto the operation of the flume, indicate that for water level in reservoir of $312.0 \mathrm{~m}$ a.s.1., the maximum obtainable spillway capacity ability reaches only $250 \mathrm{~m}^{3} \mathrm{~s}^{-1}$, which is about $135 \mathrm{~m}^{3} \mathrm{~s}^{-1}$ less than it might appear from the currently valid discharge curve for this device. The corrected discharge curve of Złotniki reservoir's spillway, for its present solutions, is shown in Fig. 3.

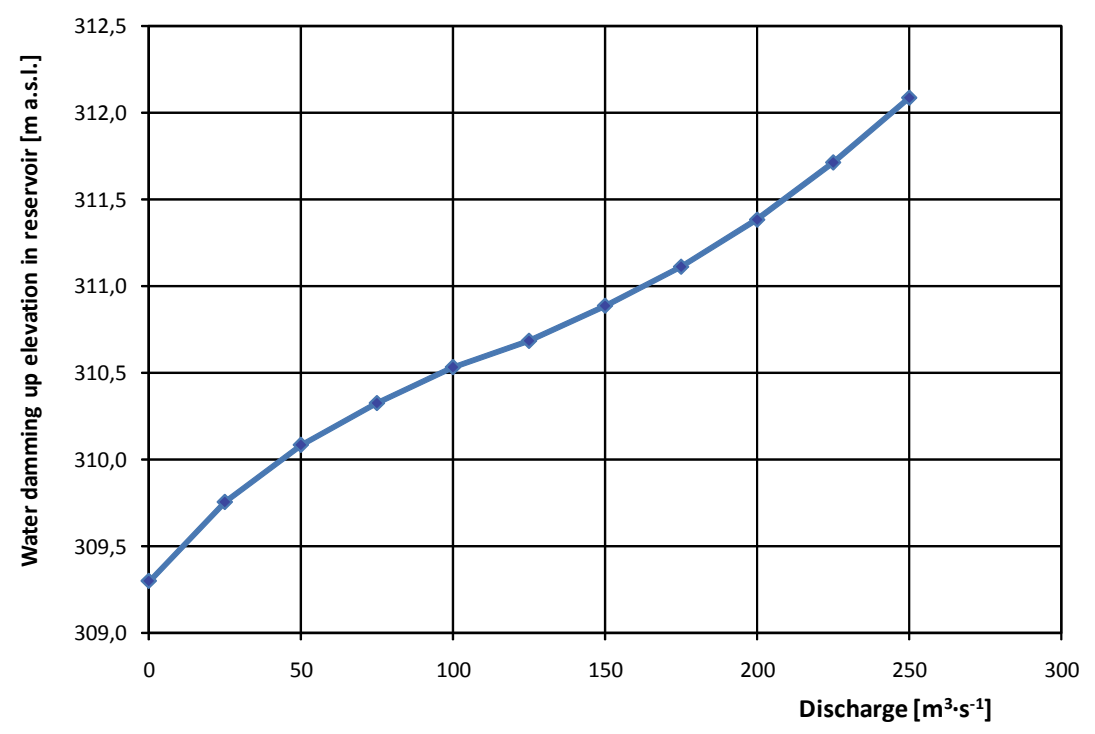

Fig. 3. Hydraulic characteristics of side channel spillway at Złotniki reservoir for the existing state (analytical)

\section{THE RIVER KWISA}

The Kwisa river is a left-sided tributary of the Bóbr river, with its mouth at $87.01 \mathrm{~km}$. The Kwisa river springs on the slopes of the Wysoki Grzbiet, at the height of about $900 \mathrm{~m}$ a.s.1. Its catchment area to the Złotniki dam cross-section equals $288.14 \mathrm{~km}^{2}$. At this section, the river is about $36.2 \mathrm{~km}$ long and its average slope is from ca. $3.5 \%$ in the mountains to ca. $1 \%$ in the foothills. The watercourses of the upper Kwisa catch- 
ment are recharged mostly from rainfall in summer and snow in winter. The hydrographical network in the upper Kwisa basin is well developed and its drainage density in this part of the basin is ca. $0.741 \mathrm{~km}^{-1}$. What is characteristic of the upper Kwisa is the occurrence of two types of floods - early spring floods in February and March, and summer floods from July to September, which is typical of Sudety rivers. Among the above-mentioned flood types, the summer ones are the heaviest while the spring ones are much lighter $[5,7]$.

On the Kwisa river, upstream of the Złotniki reservoir, there is only one gauging station located in Mirsk, the observations of which have been transferred to the dam cross-sections. Hence, the characteristic discharges are as follows (Polish abbreviations): $N N Q=0.214 \mathrm{~m}^{3} \mathrm{~s}^{-1}, S N Q=0.817 \mathrm{~m}^{3} \mathrm{~s}^{-1}, S S Q=4.449 \mathrm{~m}^{3} \mathrm{~s}^{-1}, S W Q=94.07 \mathrm{~m}^{3} \mathrm{~s}^{-1}$, $W W Q=323 \mathrm{~m}^{3} \mathrm{~s}^{-1}$ (1981), while the discharges with a given probability of exceedance are: $Q_{50 \%}=85 \mathrm{~m}^{3} \mathrm{~s}^{-1}, Q_{10 \%}=198 \mathrm{~m}^{3} \mathrm{~s}^{-1}, Q_{5 \%}=245 \mathrm{~m}^{3} \mathrm{~s}^{-1}, Q_{1 \%}=351 \mathrm{~m}^{3} \mathrm{~s}^{-1}$, $Q_{0.5 \%}=397 \mathrm{~m}^{3} \mathrm{~s}^{-1}, Q_{0.1 \%}^{\alpha}=600 \mathrm{~m}^{3} \mathrm{~s}^{-1}[5,7]$, respectively.

According to the valid regulations [9], the dam of Złotniki reservoir should be classified as class I of importance of hydrotechnical structure. For a structure of this class, founded on rock and not subjected to destruction due to overflow of its crest, the probability of exceedance for computational discharges should be $0.5 \%$ and $0.1 \%$, respectively, but only for a higher discharge with upper extension at $t_{\alpha}=1$ and confidence level 0.84. For the Złotniki dam cross-section, these discharges are:

- design discharge $Q_{m}=Q_{0.5 \%}=397 \mathrm{~m}^{3} \mathrm{~s}^{-1}$,

- control discharge $Q_{k}=Q_{0.1 \%}^{\alpha}=600 \mathrm{~m}^{3} \mathrm{~s}^{-1}$.

These discharges significantly exceed the capacity ability of the existing outlet devices of the reservoir, so the authors performed numerical analyses in order to choose the best solution for their possible reconstruction. First, the basic outlet device, i.e., a side channel spillway was analysed, as there was a possibility that it had been significantly over-dimensioned by the German designers, and because of the dominant size of its obtainable capacity ability $[4,5]$.

\section{PROPOSAL OF OUTLET DEVICES RECONSTRUCTION}

In view of the size of computational discharges and currently available (corrected) capacity ability of Złotniki reservoir's outlet devices, reservoir safety was taken into consideration when planning the reconstruction of these structures [4]. At first, the conditions of computational discharges passage through the reservoir were determined analysing a possibility of reducing them to discharges that would be safe for the downstream areas and for the reservoir itself.

The flood waves transformation through the reservoir with the existing outlet devices was analysed with the use of Puls method assumptions [2]. This method de- 
scribes flood wave passage through the reservoir by means of a continuity equation in its differential form (8)

$$
\frac{\partial Q}{\partial x}+\frac{\partial A}{\partial t}=0
$$

where:

$Q$ - discharge $\left(\mathrm{m}^{3} \mathrm{~s}^{-1}\right)$,

$x$ - coordinate consistent with water flow direction (m),

$A$ - flow cross-section area $\left(\mathrm{m}^{2}\right)$,

$t$ - time (s).

Equation (8), after being integrated in the limits from $x_{1}$ to $x_{2}$ and after the appropriate modification, assumes the form where the integral value denotes the volume of water stored in the reservoir or released from it:

$$
Q\left(x_{1}\right)-Q\left(x_{2}\right)+\frac{d}{d t} \int_{x_{1}}^{x_{2}} A d x=0 .
$$

And further, accordingly

$$
Q\left(x_{1}\right)=Q\left(x_{2}\right)+\frac{\Delta V}{\Delta t}
$$

where:

$x_{1}-$ coordinates at the reservoir inflow,

$x_{2}$ - coordinates at the reservoir outflow,

$Q\left(x_{1}\right)$ - water inflow to the reservoir $\left[\mathrm{m}^{3} \mathrm{~s}^{-1}\right]$,

$Q\left(x_{2}\right)$ - water outflow from the reservoir $\left[\mathrm{m}^{3} \mathrm{~s}^{-1}\right]$,

Equation (10), in accordance with the adopted solving procedure, could be expressed in two ways, in the differential (11) and the difference (12) forms

$$
\begin{gathered}
Q\left(x_{1}\right)=Q\left(x_{2}\right)+\frac{d V}{d t}, \\
Q\left(x_{1}\right)=Q\left(x_{2}\right)+\frac{\Delta V}{\Delta t},
\end{gathered}
$$

where $\Delta V / d t(d V / d t)$ - change in water capacity in the reservoir with time.

Knowing the flood wave hydrograph, the reservoir storage capacity curve and the characteristics of dam outlet devices, one can perform calculations of flood wave transformations through the reservoir based on equations (11) or (12). The analysis of flood wave passage through the reservoir, based on equation (12), was carried out with the use of the assumption of the above mentioned Puls method. 
The quantity $\Delta V$ denotes the volume of water stored or released from the reservoir in time $\Delta t$. Based on Puls method, numerical calculations of wave transformations through the reservoir were carried out for wave hydrographs, storage capacity curve and the characteristics of outlet devices. The following assumptions were adopted:

- A safe height difference between dam crest elevation and water level is $1.0 \mathrm{~m}$ for design discharge and $0.10 \mathrm{~m}$ for control discharge [9],

- During passage of the control flood wave through the reservoir, all the outlet devices are opened, including the turbines of the hydroelectric power plant with the total discharge of $20.29 \mathrm{~m}^{3} \mathrm{~s}^{-1}$,

- During passage of design flood wave, the following devices are out of exploitation: bottom outlet DN 1400, outlet DN 1400 of the diverse channel and turbine no. 1 with capacity of $8.95 \mathrm{~m}^{3} \mathrm{~s}^{-1}$. The remaining devices, including turbines nos. 2 and 3, are opened [9],

- The accessible relations between the reservoir water level elevation, reservoir storage capacity and the capacity ability of particular outlet devices were used to elaborate regression relations,

- Verified characteristics of the side channel spillway, based on the authors' own hydraulic calculations, were used [4],

- Allowable reservoir water level elevation was applied, corresponding to the dam crest of $312.00 \mathrm{~m}$ a.s.1.,

- Calculations for initial state of water level in reservoir at $309.30 \mathrm{~m}$ a.s.l., corresponding to the normal water level (NPP) were carried out and then verified for the conditions corresponding to the minimum water level (Min PP) in reservoir, i.e., 303.03 m a.s.1. [4].

The results of the calculations of transformation of computational flood waves [4, 5] showed that for the existing outlet devices (with the corrected spillway capacity ability) there is no possibility of maintaining a safe dam crest height over the maximum water level in the reservoir, i.e., $1.0 \mathrm{~m}$, for the passage of $Q_{m}$. discharge and $0.10 \mathrm{~m}$ for the passage of $Q_{k}$ discharge [9]. Accordingly, for the design discharge $Q_{0.5 \%}$ in the condition of initial state of water level in the reservoir at $303.03 \mathrm{~m}$ a.s.l. (Min PP), the water level in the reservoir reached the datum of $312.35 \mathrm{~m}$ a.s.l., so it overtopped the dam crest by $0.35 \mathrm{~m}$, and in the condition of initial state of water level in reservoir at $309.30 \mathrm{~m}$ a.s.1. (NPP), the water level in the reservoir reached the datum of $312.50 \mathrm{~m}$ a.s.1., so it overtopped the dam crest by $0.50 \mathrm{~m}$. Similarly, for the occurrence of $Q_{0.1 \%}^{\alpha}$ discharge, water level in the reservoir will overtop dam crest datum by $0.50 \mathrm{~m}$ for the initial state of $303.03 \mathrm{~m}$ a.s.1. and by $0.80 \mathrm{~m}$ for the initial state of $309.30 \mathrm{~m}$ a.s.l. Hence, in each computational case, water will overflow the dam crest. The results of the transformation are shown in Figs. 4 and 5.

The impossibility of a free passage of computational discharges through the existing side channel spillway is due to the fact that its flume is too shallow and too narrow 
in its upper part. By series of numerical trials consisting in assuming the flume depth and determining the free water surface along its length, the scope of work required for the reconstruction of the spillway flume was determined. It was pointed out that the channel would need deepening by at least $2.50 \mathrm{~m}$, with a simultaneous adjustment of its bottom width to $15.0 \mathrm{~m}$. Only in such conditions will it be possible to obtain the assumed spillway capacity ability for the water level in the reservoir up to the datum of $312.00 \mathrm{~m}$ a.s.1.

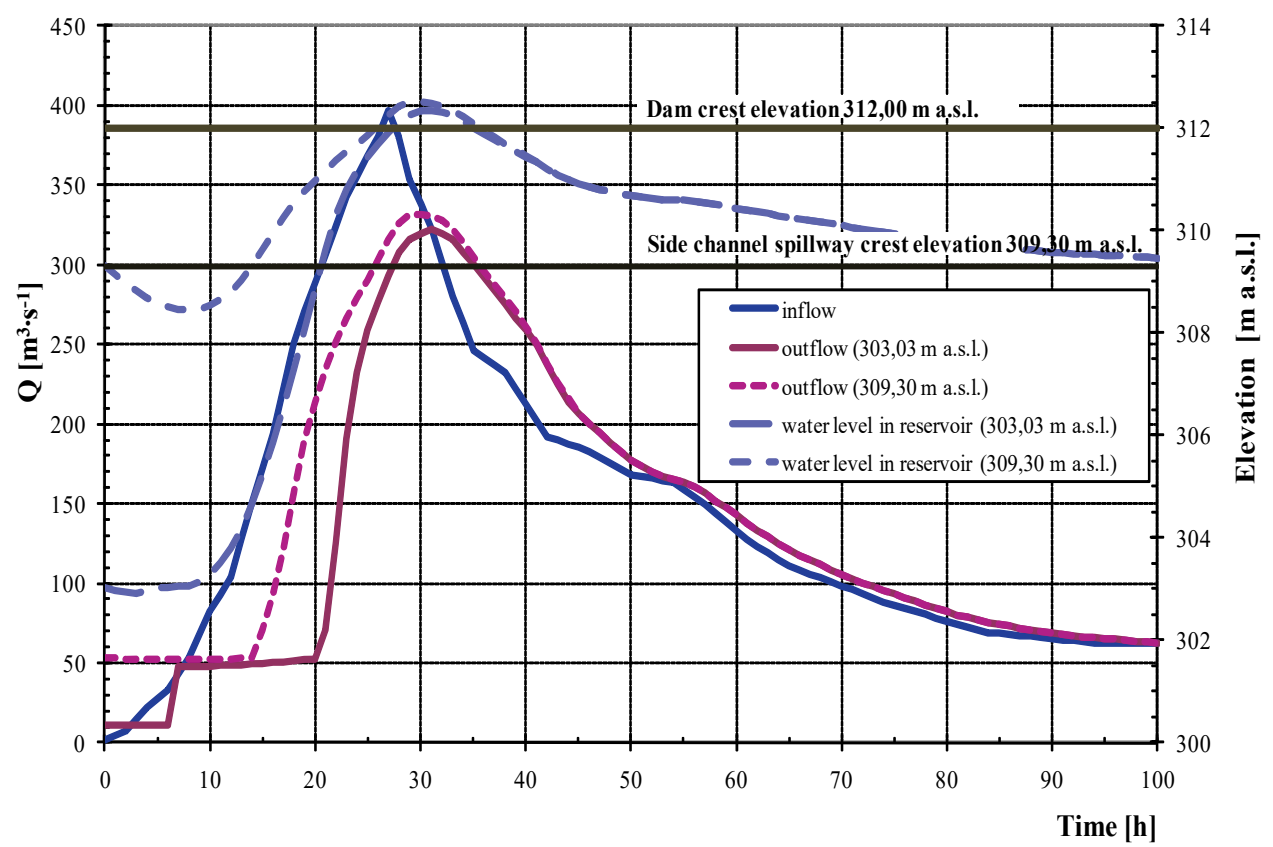

Fig. 4. Transformation of flood wave $Q_{0.5 \%}$ for the existing reservoir outlet devices (corrected spillway capacity ability), for initial state of water levels in the reservoir at 303.03 and $309.30 \mathrm{~m}$ a.s.1.

These requirements offer the possibility of the rebuilding in question, mainly in terms of economic reasons. A reconstruction would enforce the construction changes in the spillway sill (applying new static operating conditions), as well as a necessity of construction changes in the retaining wall on the opposite side - this is where the only road to the power station runs. However, significant advantages of the proposed spillway reconstruction argue for such a realization. The proposed solutions for spillway reconstruction are shown in Fig. 6.

The reconstruction of the side channel spillway could be performed without emptying the reservoir. Also, its operation safety would be preserved since the spillway is 
capable to pass flood waves without any negative consequences for the whole structure. A significant drawback of spillway reconstruction is an impossibility to improve the conditions of operating flood wave passage. In the existing state it is possible to operate the work of outlet devices (diverse channel and bottom outlets) until the water level in the reservoir reaches the spillway crest elevation, i.e., until the discharge at the outflow is slightly over $100 \mathrm{~m}^{3} \mathrm{~s}^{-1}$.

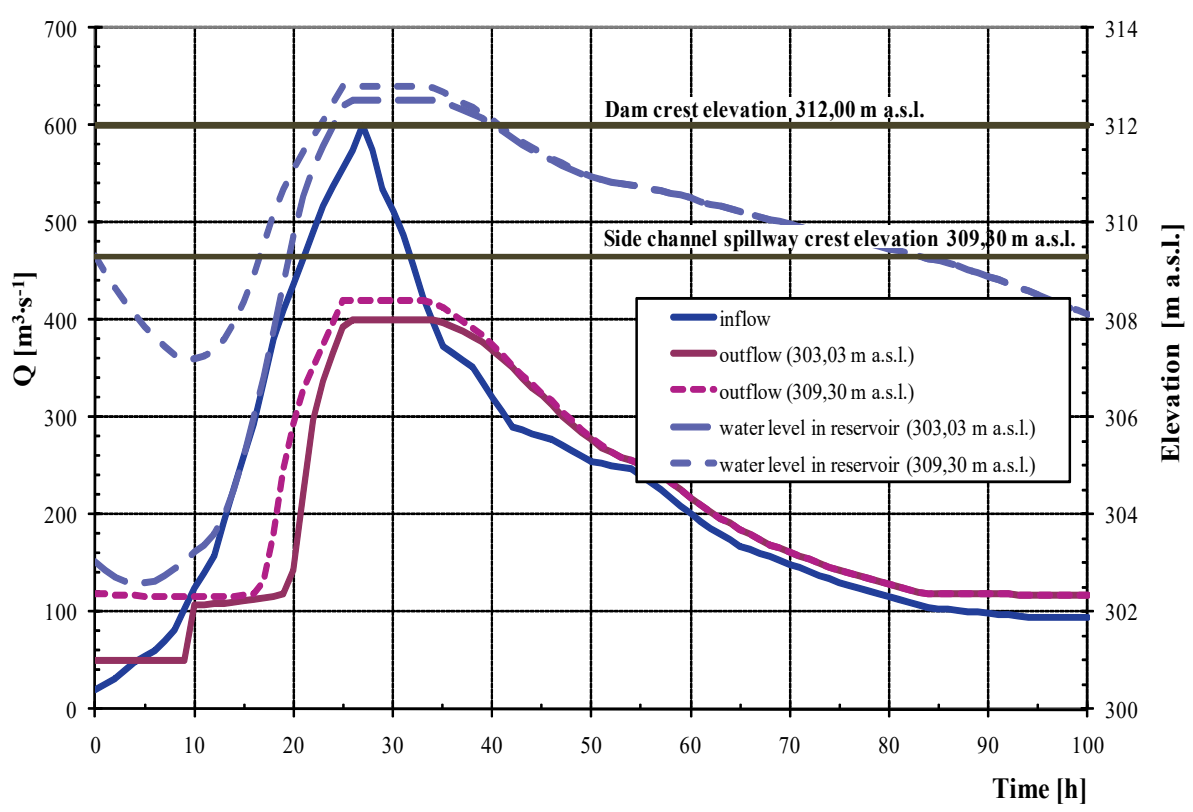

Fig. 5. Transformation of flood wave $Q_{0.1 \%}^{\alpha}$ for the existing reservoir outlet devices (corrected spillway capacity ability), for the initial state of water levels in the reservoir at 303.03 and $309.30 \mathrm{~m}$ a.s.1.

The characteristics of the side channel spillway, corrected by the analytical calculations carried out, were determined for discharges varying in the range from 0.0 to $400 \mathrm{~m}^{3} \mathrm{~s}^{-1}$ and for the water level range between $309.30 \mathrm{~m}$ a.s.l. (spillway crest) and $312.0 \mathrm{~m}$ a.s.1. (dam crest).

The hydraulic characteristics of the Złotniki reservoir side channel spillway as a function of water levels elevation in the reservoir are shown in Fig. 7, while Fig. 8 shows the discharge coefficient curve for the proposed spillway solution.

The rise of discharge curve seen in Fig. 7 and the lowering of discharge coefficient curve in Fig. 8 is where the character of spillway operation changes from not submerged to submerged one. Such a situation should not occur for devices of this type; in any conditions resulting from the parameters of the spillway and the water levels in the reservoir, this structure should work as not submerged. 


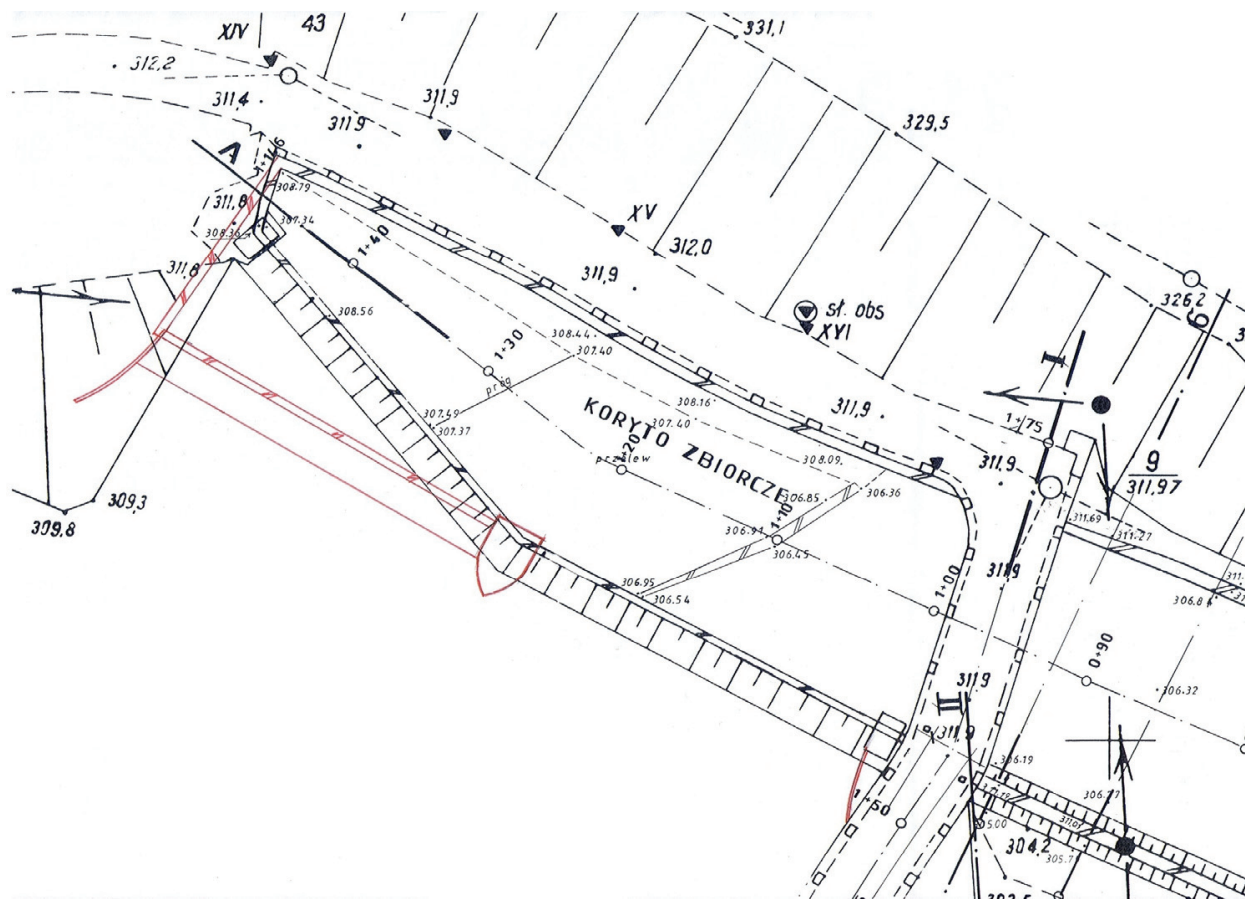

Fig. 6. Proposed reconstruction of the Złotniki reservoir spillway flume

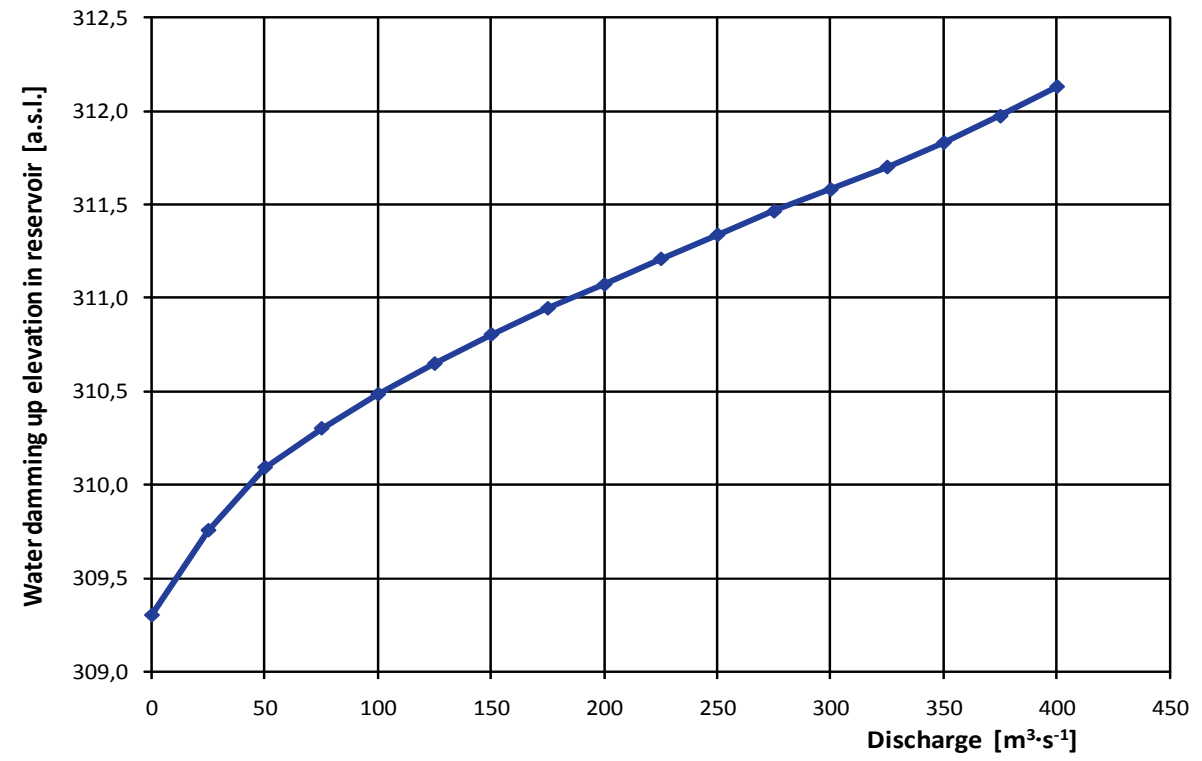

Fig. 7. Hydraulic characteristics of side channel spillway for the proposed solution 


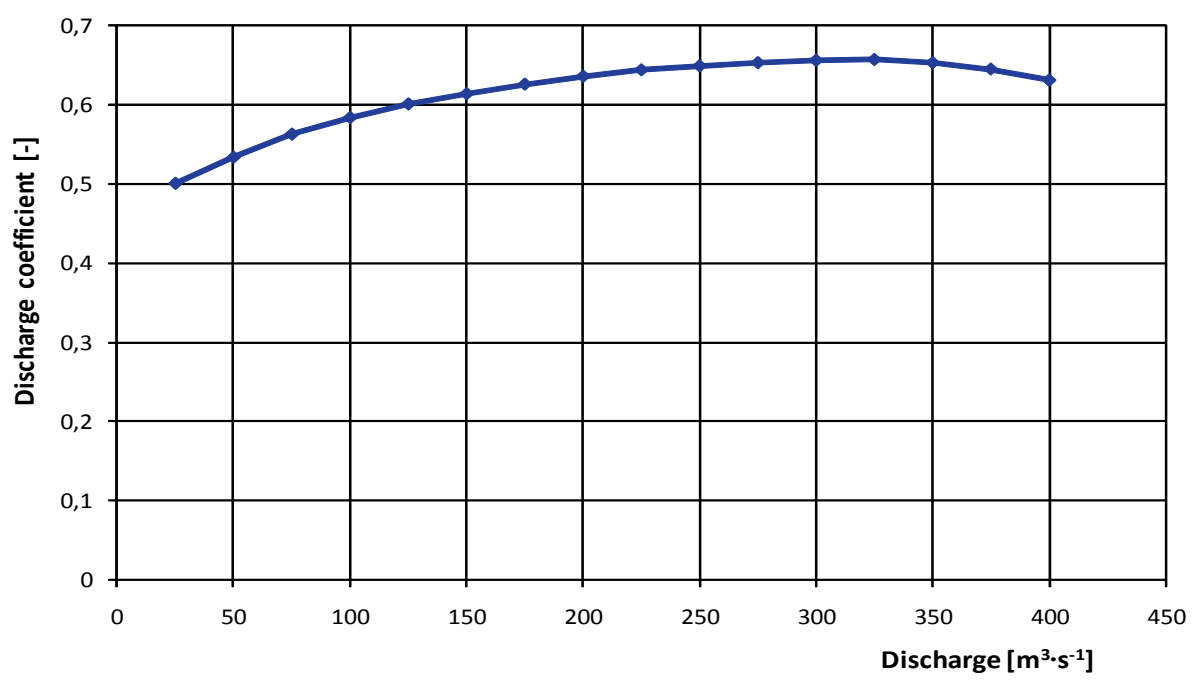

Fig. 8. Changes of discharge coefficients of side channel spillway for the proposed solution

As all the work connected with analytical calculations and the resultant concept of this device reconstruction referred to the existing structure, it was important to determine the conditions in which the character of spillway operation and the expected discharge change. The capacity ability of the spillway obtained from the numerical analyses is comparable to the calculated discharge which can flow over the spillway in specified conditions, but only on condition that the structure works as a not submerged spillway for the whole discharge range. The discharge which can be obtained for the proposed corrected spillway plane layout, its crest length, shape of spillway sill and flume parameters has the value of ca. $400 \mathrm{~m}^{3} \mathrm{~s}^{-1}$ (Fig. 6).

The numerical analyses discussed proved those remarks in professional literature that side channel spillways should be designed in such elevation configuration of flume and spillway sill that would enable them to work as not submerged in all the range of computational discharges. Then their capacity ability will be a function of the spillway crest length, thickness of overflowing water layer and the shape of the spillway sill - the shape of the crest and its overflowing part $[1,3,6,10,11,12]$.

\section{SUMMARY}

Recapitulating, the present numerical analyses of the Złotniki storage reservoir side channel spillway were connected mainly with the hydraulic characteristics of its basic components - the weir and the flume. There is a possibility of improving the capacity ability of this device and thereby improving the exploitation safety of the whole structure. 
The proposed solution that correct the bed width and configuration of the side channel spillway flume and the outflow channel linking the flume with the multistage cascade, was verified by numerical analyses [4]. This allows us to formulate the following conclusions:

1. To improve the exploitation safety of Złotniki storage reservoir it is necessary to implement the proposed changes in the existing solutions of the side channel spillway flume and in the outflow channel.

2. The changes in the solutions of the spillway flume would consist in deepening its bottom with extending onto the outflow channel, by at least $2.50 \mathrm{~m}$ in relation to its existing depth while preserving the existing longitudinal slope of both channel beds and widening the upper part of the flume.

3. The flume and the outflow channel widening and deepening will increase the capacity ability of this device by ca. $135 \mathrm{~m}^{3} \mathrm{~s}^{-1}$.

\section{REFERENCES}

[1] GHosh S.N., Flood Control and Drainage Engineering, Taylor \& Francis Group, London, 2006.

[2] JAIN S.C., Open-channel flow, John Wiley \& Sons, Inc., New York, 2001.

[3] Khatsuria R.M., Hydraulics of Spillways and Energy Dissipators, Marcel Dekker Publishers, New York, 2005.

[4] Machajski J., Olearczyk D., EW Złotniki. Reconstruction of the barrage. Proposal - Stage I, Raport serii SPR nr 5/2009, Politechnika Wrocławska, Instytut Geotechniki i Hydrotechniki, Wrocław, 2009 (in Polish).

[5] MachajSki J., OlearczyK D., RĘDOWicz W., Water management instruction for storage reservoir Złotniki, Politechnika Wrocławska, Zakład Badawczy Inżynierii Ochrony Środowiska, Jelenia Góra, 2008 (in Polish).

[6] Novak P., Moffat A.I.B., Nalluri C., Narayanan R., Hydraulic Structures, Taylor \& Francis Publishers, New York, 2007.

[7] RADCZUK L., OlEARCZYK D., Flood protection study for the Kwisa drainage basin, [in:] Hydrologia wielkich wód. Podstawy hydrologiczne dla wyznaczenia zasieggu zalewów powodziowych, Wrocławska Agencja Rozwoju Regionalnego, Wrocław, 2006 (in Polish).

[8] Rogala R., Machajski J., RęDowicz W., Applied Hydraulics. Model calculations, Wydawnictwo Politechniki Wrocławskiej, Wrocław, 1991 (in Polish).

[9] Ministry of Environment Protection Regulation of 20 April 2007 on technological conditions required for hydrotechnical structures and their location, Journal of Laws, No. 86/2007, pos. 579 (in Polish).

[10] ŞENTÜRK F., Hydraulics of Dams and Reservoirs, Water Resources Publications, Colorado, 1994.

[11] TANČEV L., Dams and Appurtenant Hydraulic Structures, A.A. Balkema Publishers, London, 2005.

[12] Vischer D.L., Hager W.H., Dam Hydraulics, John Wiley \& Sons, Chichester, 1998. 